\title{
The Effect of Electroacupuncture Therapy on Pain, Plasma $\beta$-Endorphin, and Quality of Life of Stage III Cervical Cancer Patients: A Randomized Control Trial
}

\author{
Wita Saraswati ${ }^{1, *}$, Ratih Wardani ${ }^{1}$, Suhatno Suhatno ${ }^{1}$, Pudjo Hartono ${ }^{1}$, Ario Imandiri² \\ ${ }^{1}$ Department of Obstetrics and Gynecology, Faculty of Medicine, Universitas Airlangga - Dr. Soetomo General Academic Hospital, \\ Surabaya, Indonesia \\ ${ }^{2}$ Department of Traditional Healer, Faculty of Vocations, Universitas Airlangga, Surabaya, Indonesia
}

Received August 15, 2019

Revised November 18, 2020

Accepted December 28, 2020

Correspondence to

Wita Saraswati

Department of Obstetrics and

Gynecology, Faculty of Medicine,

Universitas Airlangga - Dr. Soetomo

General Academic Hospital, Surabaya,

Indonesia

E-mail wita.saraswati@fk.unair.ac.id
Background: Pain is a major complaint in cancer patients and a global problem that requires medical attention, including pain in cervical cancer. Although pharmacotherapy has been used for the treatment of cancer pain, there are still around $40 \%$ cannot be treated only with pharmacotherapy.

Objectives: To determine the effects of electroacupuncture (EA) on pain in stage III cervical cancer patients.

Methods: Twenty-eight stage III cervical cancer patients were divided into two groups (14 treatments and 14 controls) with randomized control trial design. The treatment group received EA with a frequency of $2 / 20-25 \mathrm{~Hz}$ at points of ST36, SP6, LI4 and LR3 for 30 minutes, while the control group did not receive EA. Both groups were given paracetamol and codeine at the same dose. Assessment was carried out by measuring pain scale (VAS), plasma $\beta$-endorphin levels, and quality of life/QoL (EORTC QLQ-C30) before and after therapy.

Results: The average reduction in VAS in the treatment group $(2.71 \pm 1.14)$ compared to the control group $(0.71 \pm 1.33 ; p<0.001)$, average increase in plasma $\beta$-endorphin levels in the treatment group $(88.57 \pm 52.46 \mathrm{pg} / \mathrm{ml})$ compared to the control group $(12.86 \pm 56.76$ $\mathrm{pg} / \mathrm{ml} ; p=0.001$ ), and in QoL, there were significant differences in symptom improvement between the treatment and control groups in the domain of fatigue, pain, insomnia and overall QoL $(p<0.05)$.

Conclusion: Medical therapy combined with EA decreased pain scale, increased plasma $\beta$-endorphin levels, and improved the QoL for stage III cervical cancer patients.

Keywords: Electroacupuncture, VAS, $\beta$-endorphin, Quality of life, Cervical cancer

\section{INTRODUCTION}

Almost all cancer patients have pain complaint at a time in their lives. At an advanced stage, $>80 \%$ of cancer patients have moderate to severe pain. The prevalence of worldwide cancer pain is around 25\% in new cancer patients, $33 \%$ in cancer patients who have received treatment, and more than $75 \%$ in advanced cancer patients [1]. Even 33\% cancer survivors, who have received complete therapy, still suffer from chronic pain [2]. Many patients and clinicians consider that pain complaints are reasonable in advanced cancer patients or terminals [3].

In the field of gynecology, cervical cancer is the leading cause of cancer death in women. Most cervical cancers are diagnosed at an advanced stage and even terminal. Pain is the most common complaint in cervical cancer, so pain management becomes a priority. A study found that of 100 cervical cancer patients, $78 \%$ of them had pain complaint in the last 1 week [4]. Pain is a major complaint of cervical cancer. However, there have been no studies that specifically examine cervical cancer pain management and complementary therapy (medical therapy). Research has shown that at least $20-40 \%$ of cancer pain is not adequately resolved despite therapy in accordance with the WHO guidelines for handling pain $[5,6]$.

Unresolved pain greatly affects all aspects of quality of life (QoL), the patient's ability to adhere to treatment, ability to restore the patient's motivation to be healthy, and even leads 
to terminal state or peaceful death [7]. In 2007, WHO along with International Pain Community pointed cancer pain as a global health problem [8]. The results of Metanalysis stated the prevalence of cancer pain by $39.5 \%$ after curative therapy, $55 \%$ during anti-cancer therapy, and $66.4 \%$ at advanced stages, metastases or terminal stages. The pain can be treated in accordance with the pain management of the WHO guidelines. However, the data showed that there are still about $40 \%$ unresolved pain cases with these guidelines, so that supporting therapy is needed to deal with pain [9].

Non-pharmacological complementary therapy (complementary medicine) is generally considered to be relatively safe and is often used as an additional therapy for other standard pain management [10]. One additional therapy is electroacupuncture (EA) as a reduction option or pain relief that almost have no side effects, safe, easy and can reduce drug usage by $80 \%$, although the therapy requires a long time. The analgesic effect of the EA method was recognized by WHO and was licensed by the food and drug administration (FDA) in 1996 [11].

The working mechanism of electroacupuncture can be at the local, segmental, and central level, which is the hypothalamic-pituitary pathway that becomes active due to needle puncture and results in endogenous opioid secretion. Betaendorphins are secreted to blood vessels and brain fluid (CSF), and this endorphin will work directly on the pain pathway in the central nervous system and spinal cord as a neurotransmitter. This will cause analgesia and homeostatic effects on several systems, including the immune, cardiovascular, respiratory, and healing processes $[12,13]$. In addition, EA is also believed to reduce the symptoms caused by cancer and therapeutic side effects to improve the QoL of patients [14].

Over the past 20 years, there have been many studies reporting on the use of EA to treat cancer pain, but the results of these studies are inconsistent, so clinicians still have difficulty in making decisions to involve EA therapy in the treatment plan for patients with cancer pain [15]. Based on the description above, the researchers aimed to determine the effect of EA and conventional pain treatment, plasma $\beta$-endorphin levels, and QoL for stage III cervical cancer patients.

\section{MATERIALS AND METHODS}

\section{Participants}

Participants in this study were cervical cancer patients treated at Dr. Soetomo General Hospital, Surabaya, Indonesia. The inclusion criteria included patients diagnosed with cervical cancer clinically and stage III histopathology based on WHO categorization [11,13,16]; aged 18-65 years; pain scale $>4$ based on VAS (Visual Analog Scale); and patients cooperatively took conventional pain therapy and EA according to the research schedule. Participant exclusion criteria included patients experiencing pain that was not caused by cervical cancer; pain due to chemotherapy (neuropathy); pain due to surgery; had received $<1$ week of anti-pain therapy; patients with pregnancy, wounds/ tumors in the area of stabbing, blood clotting abnormalities, installation of pacemakers, extensive skin abnormalities including ear skin; patients with physical disabilities that were not possible to do acupuncture therapy; and patients had or were undergoing chemotherapy and/or radiation. The participant first received an explanation of the research procedure, and completed the consent forms before carrying out the research.

\section{Ethical approval}

This study has obtained a certificate of ethical clearance according to Declaration of Helsinki from ethical committee team in Dr. Soetomo General Academic Hospital, Surabaya, Indonesia (389 / Panke.KKE / V / 2017).

\section{Study design}

An experimental research using randomized control trial design was conducted in June to December 2017 at Dr. Soetomo General Academic Hospital, Surabaya, Indonesia. Participants were 28 cervical cancer patients (14 patients in the treatment group and 14 control group patients) who were obtained by consecutive sampling method (Fig. 1). Distribution of treatment groups and control groups was randomized. The procedure of this study included the treatment group received medical therapy plus EA, while the control group only received medical therapy (paracetamol $4 \times 500 \mathrm{mg}$ and codeine $4 \times 10 \mathrm{mg}$ ). EA was given 10 times in 3 weeks, while medical therapy was given every day for 3 weeks. Before and after EA and medical therapy, participants measured the pain scale, plasma $\beta$-endorphin levels and QoL.

\section{Electroacupuncture (EA)}

The procedure for implementing EA in this study is based on the Guideline Standards for Reporting Interventions in Clinical Trials of Acupuncture (STRICTA) [17]. Electroacupuncture was placed at LI4, ST36, SP6, and LR3 for 30 minutes with disperse dense wave (DD), and used a combination frequency of $2 / 20-25 \mathrm{~Hz}$. The LI4 point was located on the dorsum manus, the middle radial side of the second metacarpal bone (between metacarpal bone I and II), with a depth of $0.8-1.3$ cun perpendicular. Vascularized by dorsal manus radial arteries, and innervated by the superficial ramus of radial nerve [18]. ST36 lied on the anterior lateral limb, such as the point on 3 cun or 4 fingers under the patella 


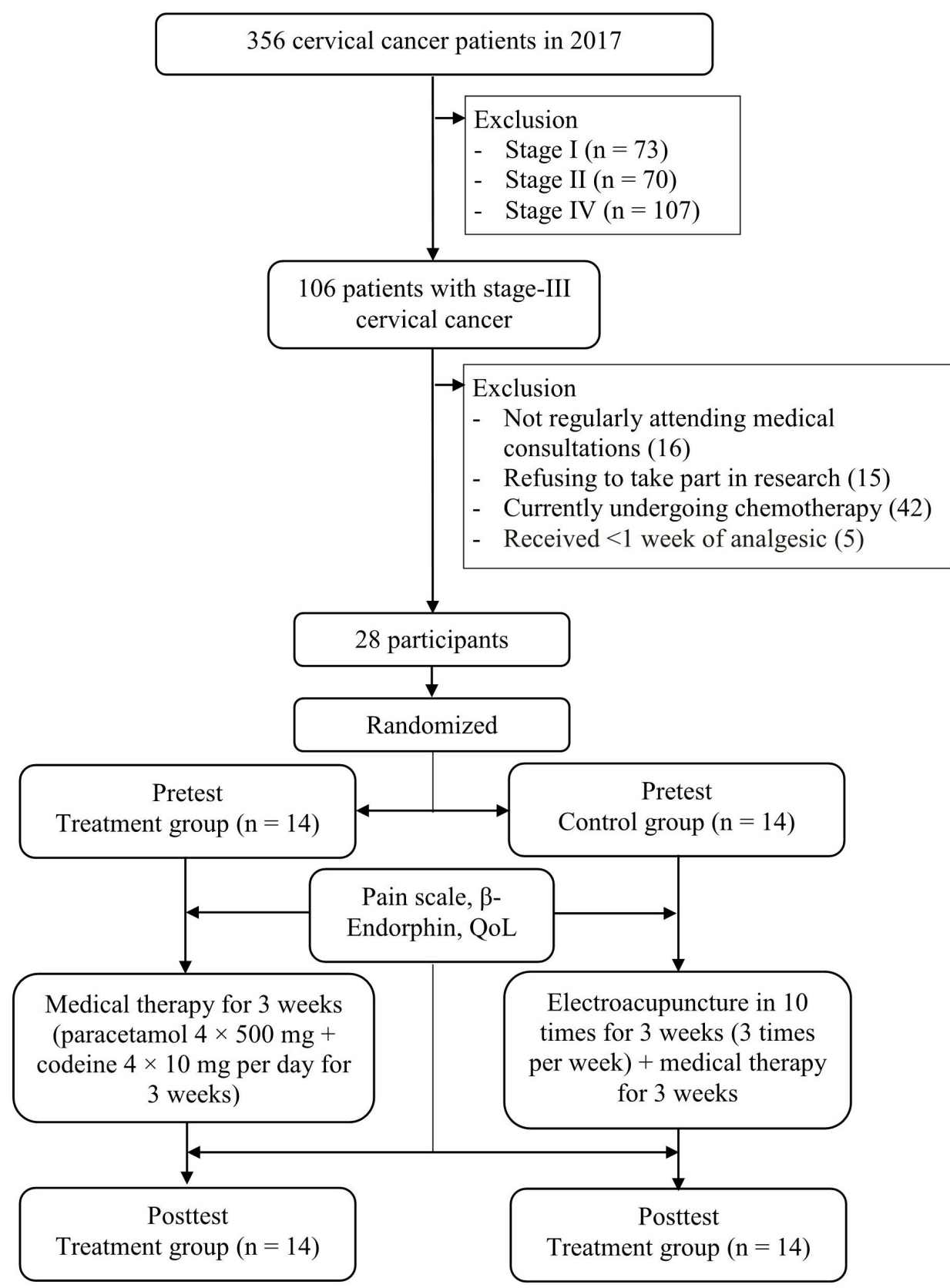

Fig. 1. The process of participant recruitment.

(under the hole if the knee is flexed), 1 cun lateral tibia crest as deep as $0.5-1.3$ cun perpendicular. Vascularized by the anterior tibial arteries, innervated by the lateral cutaneous nerve of the lower limb [11]. SP6 was on the tibial side of the lower limb, the posterior part of the medial tibia, which was located at 3 cun or 4 fingers above the medial malleolus (3 inches above the medial malleolus), posterior to the tibia with a stab depth of 0.5-0.9 cun direction needle towards the tibia. Vascularized by saphenous vein magna, and posterior tibial artery [19]. LR3 was on the dorsal leg, between the first and second metatarsal bones, in the curvature of distal of the meeting of the two bones, beside the dorsalis pedis artery, with a puncture depth of 0.5 cun perpendicular. Vascularized by the dorsalis pedis vein, dorsalis-1 metatarsal arteries, innervated by the cutaneous nerves of the dorsal medial dorsal, and the deep peroneal nerve [20].

Electroacupuncture was given to participants 10 times every 2 days ( 3 weeks) at acupuncture points using stainless needles (Huanqiu) of $0.25 \times 25 \mathrm{~mm}$ in symmetrical right and left (bilateral) body parts. Needle puncture to a depth of 10-15 mm, then connected to the EA device (KWD-808 I Multi-Purpose Health Device with 6 channels). Electrical stimulation was given with dense disperse (DD) wave at $2 / 20$ $25 \mathrm{~Hz}$ for 30 minutes. This EA was operated by a certified 
acupuncturist.

\section{Visual analogue scale (VAS)}

Visual analog scale (VAS) is a special scale used to measure a person's pain level on a scale of 1 to 10. VAS measurements were performed before and after the participant took EA treatment.

\section{6. $\beta$-endorphin}

The examination of plasma $\beta$-endorphin levels was carried out by taking $\pm 3 \mathrm{ml}$ participant blood samples that were stored in a Lavender Vacutaner tube containing EDTA at a temperature of $2-8^{\circ} \mathrm{C}$. The tube was inserted into the cooler box and delivered to Prodia Clinical Laboratory with a cooler box (blood in a cold atmosphere). The blood sample was immediately added with aprotinin $20 \mu$ l, before being centrifuged $1,600 \mathrm{~g}$ for 15 minutes at $4^{\circ} \mathrm{C}$ to take as much blood plasma as 3 plasma sample cup at $0.3 \mathrm{ml}$. Blood plasma was stored in a cooler at $-70^{\circ} \mathrm{C}$ until all samples were collected. After all samples were collected, endorphins were tested by Prodia Clinical Laboratory officers, Jakarta, Indonesia. $\beta$-endorphin in plasma serum was identified using an enzyme-linked immunosorbent assay (ELISA) (MD Biosciences, Zürich, Switzerland). Participant blood samples were taken twice, before and after EA therapy.

\section{Quality of life (QoL)}

In this study, QoL is referred to health-related quality of life (HRQOL) which describes the functional effects of the disease and the therapeutic consequences felt by the patient. The data were obtained from interviews using a cancerspecific questionnaires, such as the European Organization for Research and Treatment of Cancer Quality of Life Questionnaire-Core30 (EORTC QLQ-C30) in the Indonesian version [21]. QoL assessments were carried out before and after EA in participants.

\section{Data analysis}

The obtained data were processed using the SPSS 23.0 program (IBM Corp., Armonk, NY, USA). Data normality test was conducted using Shapiro-Wilk test, and the data were normally distributed if $p>0.05$. If the data were normally distributed, the data were displayed with mean and standard deviation (SD). However, if the data were not normally distributed, the data were displayed with a median value (minimum-maximum). To determine the effects of both treatments in each group, the study compared the average reduction in pain scale (VAS), changes in QoL and plasma $\beta$-endorphins levels pre- and post-test in each group. If the data were normally distributed, we examined changes in the pre-test and post-test values of each group by performing parametric statistical tests with paired samples t-test, while the average differences between the groups were compared using independent paired t-test $(p<0.05)$. If the data were abnormally distributed, we examined changes in the pretest and post-test values of each group using non-parametric statistical tests with the Wilcoxon Signed Ranks Test, while the difference in changes in scores between groups was compared using Mann-Whitney Test $(p<0.05)$.

\section{RESULTS}

\section{Characteristics of participant}

Participants did not have a significant age difference in the two groups (treatment and control). Most participants in the treatment group were $36-45$ years old $(42.86 \%)$ and most participants in the control group were 46-55 years old (64.29\%). Average age of participants in the treatment group were $45.28 \pm 12.62$ years and average age of participants in the control group were $52.50 \pm 5.78$ years. Most participants in the treatment group had junior high school educational background (35.71\%), while most participants in the control group had elementary school educational background (35.71\%). Most participants were housewives as much as $64.29 \%$ in each group (Table 1 ).

Table 1. Participants' characteristics

\begin{tabular}{lccc}
\hline \multicolumn{1}{c}{ Variable } & \multicolumn{2}{c}{ Group } & \\
\cline { 2 - 3 } & $\begin{array}{c}\text { Treatment } \\
(\mathrm{n}=14)\end{array}$ & $\begin{array}{c}\text { Control } \\
(\mathrm{n}=14)\end{array}$ \\
\hline Age & $45.28 \pm 12.62$ & $52.50 \pm 5.78$ & 0.068 \\
$26-35$ & $4(28.57)$ & $0(0.00)$ & \\
$36-45$ & $6(42.86)$ & $1(7.14)$ \\
$46-55$ & $1(7.14)$ & $9(64.29)$ \\
$56-65$ & $1(7.14)$ & $4(28.57)$ \\
$>65$ & $2(14.28)$ & $0(0.00)$ \\
Education & $2(14.28)$ & $1(7.14)$ \\
Not attending school & $4(28.57)$ & $5(35.71)$ \\
Elementary school & $5(35.71)$ & $4(28.57)$ \\
Junior high school & $2(14.28)$ & $3(21.43)$ \\
Senior high school & $1(7.14)$ & $1(7.14)$ \\
Undergraduate & & \\
Occupation & $9(64.29)$ & $9(64.29)$ \\
Housewife & $1(7.14)$ & $3(21.43)$ \\
Public servants & $4(28.57)$ & $2(14.28)$ \\
Private sector & & \\
employee or & & \\
entrepreneur & & \\
\hline
\end{tabular}

Numerical data is shown as mean \pm standard deviation, while categorical data is shown as frequency (percentage). 


\section{Effect of electroacupuncture therapy on pain scale and plasma $\beta$-endorphin levels}

The average VAS value of the treatment group before EA therapy was $6.36 \pm 1.15$, and after EA therapy for 3 weeks, the average VAS value was $3.64 \pm 1.39(p<0.001)$. The average VAS values in the control group at the beginning of data collection was $6.07 \pm 1.14$, and after three-week therapy, the average VAS value was $5.36 \pm 1.86(p=0.065)$. Both groups experienced a decrease in the pain scale. The treatment group experienced a significant decrease of $2.71 \pm 1.14$, while the control group was only $0.71 \pm 1.33(p<0.001)$. The average plasma $\beta$-endorphin level before EA therapy in the treatment group was $102.86 \pm 66.73 \mathrm{pg} / \mathrm{ml}$, and after EA therapy for 3 weeks, the level was increased to $191.43 \pm 65.49 \mathrm{pg} / \mathrm{ml}(p<$ 0.001). The average plasma $\beta$-endorphin level at the initial examination of the control group was $148.57 \pm 98.28 \mathrm{pg} / \mathrm{ml}$, while after 3 weeks, plasma $\beta$-endorphin levels were $161.43 \pm$ $73.47 \mathrm{pg} / \mathrm{ml}(p=0.412)$. There was an increase in $\beta$-endorphin levels in both groups, but the increase in $\beta$-endorphin levels in the treatment group was higher at $88.57 \pm 52.46 \mathrm{pg} / \mathrm{ml}$, while the increase in $\beta$-endorphin levels in the control group was $12.86 \pm 56.76 \mathrm{pg} / \mathrm{ml}$ group $(p=0.001$; Table 2$)$.

\section{Effect of electroacupuncture therapy on quality of life}

On the overall QoL domain, there was a significant increase in score changes $(p<0.001)$. Participants in the treatment group experienced an increase in the QoL $(p=0.001)$, but the overall QoL in the control group showed no change before and after therapy $(p=1.000)$. On the functional scale, such as the physical domain, role, emotional, cognitive, and social domain, both treatment and control groups experienced an increase in scores (improvement) even though the increase was not significant $(p>0.05$; Table 3$)$.

The fatigue domain experienced a significant decrease in scores both in the treatment group $(p=0.001)$ and control $(p=$ 0.038 ), but the treatment group experienced a lower decline than the control group $(p=0.012)$. The pain domain also experienced a significant decrease in scores in the treatment group $(p=0.001)$ and the control group $(p=0.034)$, but the treatment group experienced a lower decrease in scores compared to the control group $(p=0.020)$. The domain of sleep difficulties also decreased both in the treatment group ( $p$ $=0.001)$ and the control group $(p=0.059)$, but the treatment group experienced a decrease in scores compared to the control group $(p=0.005)$. The domain of decreased appetite also decreased in both the treatment group $(p=0.010)$ and the control group $(p=0.450)$, but the treatment group and the control group did not have a significant comparison $(p$ $=0.064)$. In the domain of nausea, vomiting, congestion, constipation, diarrhea, and finance, both in the treatment group and the control group experienced an increase in scores

Table 2. Average VAS score and plasma $\beta$-endorphin level pre- and post-therapy

\begin{tabular}{llccccc}
\hline \multicolumn{1}{c}{ Variable } & Group & Pre-test & Post-test & Difference & $p_{\alpha}$ & $p_{\beta}$ \\
\hline VAS score & Treatment & $6.36 \pm 1.15$ & $3.64 \pm 1.39$ & $2.71 \pm 1.14$ & $0.000^{*}$ & $0.000^{*}$ \\
& Control & $6.07 \pm 1.14$ & $5.36 \pm 1.86$ & $071 \pm 1.33$ & 0.065 & \\
Plasma $\beta$-endorphin level & Treatment & $102.86 \pm 66.73$ & $191.43 \pm 65.49$ & $88.57 \pm 52.46$ & $0.000^{*}$ & $0.000^{*}$ \\
& Control & $148.57 \pm 98.28$ & $161.43 \pm 73.47$ & $12.86 \pm 56.76$ & 0.412 & \\
\hline
\end{tabular}

$p_{\alpha}=p$-value using paired t test; $p_{\beta}=p$-value using independent $t$ test; *significant $p<0.05$.

Table 3. Quality of life in global health status and functional pre- and post-therapy

\begin{tabular}{|c|c|c|c|c|c|}
\hline Variable & Group & Pre-test & Post-test & $p_{\alpha}$ & $p_{\beta}$ \\
\hline \multirow[t]{2}{*}{ Overall QoL } & Treatment & $41.67(33.33-66.67)$ & $58.33(41.67-83.33)$ & $0.001 *$ & $0.000 *$ \\
\hline & Control & $50.00(33.33-66.67)$ & $50.00(33.33-66.67)$ & 1.000 & \\
\hline \multirow[t]{2}{*}{ Physical } & Treatment & $70.00(60.00-100.00)$ & $73.33(66.67-100.00)$ & 0.059 & 0.782 \\
\hline & Control & $70.00(60.00-100.00)$ & $73.33(60.00-100.00)$ & 0.129 & \\
\hline \multirow[t]{2}{*}{ Role } & Treatment & $66.67(33.33-66.67)$ & $66.67(33.33-83.33)$ & 0.063 & 0.628 \\
\hline & Control & $66.67(33.33-83.33)$ & $66.67(33.33-83.33)$ & 0.060 & \\
\hline \multirow[t]{2}{*}{ Emotion } & Treatment & 58.33 (16.67-83.33) & $62.50(16.67-91.67)$ & 0.461 & 0.566 \\
\hline & Control & $58.33(16.67-91.67)$ & $58.33(16.67-91.67)$ & 0.063 & \\
\hline \multirow[t]{2}{*}{ Cognitive } & Treatment & $83.33(66.67-100.00)$ & $83.33(66.67-100.00)$ & 0.063 & 0.304 \\
\hline & Control & 66.67 (66.67-100.00) & $83.33(66.67-100.00)$ & 0.157 & \\
\hline \multirow[t]{2}{*}{ Social } & Treatment & 41.67 (16.67-66.67) & $50.00(16.67-66.67)$ & 0.059 & 0.738 \\
\hline & Control & $58.33(16.67-66.67)$ & $66.67(16.67-66.67)$ & 0.083 & \\
\hline
\end{tabular}

$\mathrm{QoL}=$ Quality of life; $p_{\alpha}=p$-value using Mann withney test; $p_{\beta}=p$-value using wilcoxon test; *significant $p<0.05$. 
Table 4. Quality of life in symptom scale pre- and post-test therapy

\begin{tabular}{|c|c|c|c|c|c|}
\hline Variable & Group & Pre-test & Post-test & $p_{\alpha}$ & $p_{\beta}$ \\
\hline \multirow[t]{2}{*}{ Fatigue } & Treatment & $72.17(33.33-89.00)$ & $44.33(41.67-66.67)$ & $0.001 *$ & $0.012^{*}$ \\
\hline & Control & $66.67(33.33-77.67)$ & $66.67(33.33-77.67)$ & $0.038^{*}$ & \\
\hline \multirow[t]{2}{*}{ Nausea-vomit } & Treatment & $0.00(0.00-66.67)$ & $0.00(0.00-66.67)$ & 0.317 & 0.317 \\
\hline & Control & $0.00(0.00-16.67)$ & $0.00(0.00-16.67)$ & 1.000 & \\
\hline \multirow[t]{2}{*}{ Pain } & Treatment & $100.00(66.67-100.00)$ & $66.67(16.67-83.33)$ & $0.001^{*}$ & $0.020^{*}$ \\
\hline & Control & 66.67 (16.67-100.00) & $66.67(16.67-100.00)$ & $0.034^{*}$ & \\
\hline \multirow[t]{2}{*}{ Shortness of breath } & Treatment & $0.00(0.00-33.33)$ & $0.00(0.00-33.33)$ & 1.000 & - \\
\hline & Control & $0.00(0.00-33.33)$ & $0.00(0.00-33.33)$ & 1.000 & \\
\hline \multirow[t]{2}{*}{ Sleeping difficulty } & Treatment & $66.67(33.33-100.00)$ & $33.33(0.00-100.00)$ & $0.001^{*}$ & $0.005^{*}$ \\
\hline & Control & $66.67(33.33-100.00)$ & $33.33(0.00-100.00)$ & 0.059 & \\
\hline \multirow[t]{2}{*}{ Decreased appetite } & Treatment & $33.33(00.00-100.00)$ & $33.33(0.00-66.67)$ & $0.010^{*}$ & 0.064 \\
\hline & Control & $33.33(33.33-66.67)$ & $33.33(0.00-66.67)$ & 0.450 & \\
\hline \multirow[t]{2}{*}{ Constipation } & Treatment & $16.67(0.00-66.67)$ & $0.00(0.00-66.67)$ & 0.102 & 0.693 \\
\hline & Control & $33.33(0.00-66.67)$ & $16.67(0.00-33.33)$ & 0.059 & \\
\hline \multirow[t]{2}{*}{ Diarrhoea } & Treatment & $0.00(0.00-33.33)$ & $0.00(0.00-0.00)$ & 1.000 & - \\
\hline & Control & $33.33(0.00-33.33)$ & $0.00(0.00-0.00)$ & 0.317 & \\
\hline \multirow[t]{2}{*}{ Financial } & Treatment & $33.33(00.00-33.33)$ & $3.33(0.00-66.67)$ & 0.063 & 0.109 \\
\hline & Control & $33.33(00.00-33.33)$ & $33.33(0.00-66.67)$ & 0.655 & \\
\hline
\end{tabular}

$p_{\alpha}=p$-value using Mann withney test; $p_{\beta}=p$-value using wilcoxon test; *significant $p<0.05$.

(improvement) even though the increase was not significant $(p>$ 0.05; Table 4).

\section{DISCUSSION}

A total of 8 acupuncture points were used (four points on either side of the bilateral side) in this study, such as two LI4 points, two ST36 points, two SP6 points, and two LR3 points. The combination of several points were expected to produce a stronger analgesic effect than using only one or two points. The selection of these points was based on empirical evidence. Manipulation at LI4 point, both manually and with electrostimulator, would increase the pain threshold. The peak occurred in 20-40 minutes after acupuncture treatment and lasted more than 30 minutes [20]. This stimulation LI4 point in healthy people could activate Periaquaductal Gray (PAG) and Nucleus Raphe Magnus (NRM) which does not occur in non-acupuncture points, therefore LI4 is widely used for analgesia [22,23].

Imaging in the brain, in manual stimulation at ST36 point activates the anterior and posterior insula area, medial thalamus, inferior parietal lobe and secondary sensory somatic cortex. Particularly, anterior insula is an important area involved in visceral pain [24]. Low-frequency electroacupuncture stimulation using ST36 point has been shown to reduce allodynia pain where the effect is mediated by GABA spinal receptors [25]. The application of EA at ST36 point four times within a week interval was shown to increase the number of NK cells, IFN- $\gamma$ levels, Th1/Th2 ratio, appetite score and shrink tumor volume significantly, while also reducing pain scores and nausea and vomiting scores even though not significant [11]. Electroacupuncture at SP6 point and LI4 point will also activate the PAG, NRM and hypothalamus areas involved in pain modulation, whereas LR3 is empirically often used for pain in the lower abdominal area and postoperative gynecological pain $[22,26]$.

This study used EA with combination waves or commonly referred to as dense disperse (DD) wave, with a frequency of 2/20-25 Hz. The intensity ranged until the patient had felt the wave. Disperse dense wave was chosen to achieve optimal effects of acupuncture. The maximum analgesia effect was obtained from the use of EA DD wave at frequency of 2/100 $\mathrm{Hz}$ compared to the use of a single EA frequency of $2 \mathrm{~Hz}$ or $100 \mathrm{~Hz}$ only. The EA DD wave frequency of $2 / 100 \mathrm{~Hz}$ caused a reduction in postoperative morphine requirements of $53 \%$, whereas a single EA frequency of $2 \mathrm{~Hz}$ or $100 \mathrm{~Hz}$ morphine requirements only reduced by $32 \%$ and $35 \%$ respectively. It can be concluded that the use of EA DD waves is better and faster in causing analgesia, if combined with anesthetic drugs will achieve an optimal effect [24].

Pain level (VAS score) in both participant groups had decreased. The acupuncture therapy and administration of analgesic drugs in accordance with WHO step ladder are more effective in reducing pain than analgesic treatment [27]. A significant reduction in pain intensity in the VAS score after the procedure was achieved by the acupuncture group compared to the placebo group [27]. Acupuncture is no more effective than medical, but acupuncture combined with medical treatment is more effective in reducing pain compared to only medical therapy [28]. 
The effects of acupuncture therapy occur at various levels in the nervous system, both in peripheral, segmental (spinal) and central levels. In peripheral, acupuncture will stimulate nerve fibers $A \beta, A \delta$ and $C$. Specifically, activation of nerve fibers $A \delta$ and $C$ is important for modulation of pain and activity of the autonomic nervous system. These stimuli cause the release of neuropeptide calcitonin gene related peptides and vasoactive intestinal polypeptides from peripheral nerve terminals and other vasodilation mediators, such as adenosine and nitric oxide from tissues around the needle area, resulting in increased blood flow. Overall, these findings suggest that local needle puncture can increase blood flow and nutrient uptake, factors that may be impaired in ischemic and degenerative pain conditions [29].

At the segmental level, the role of pain inhibition is illustrated through gate control theory. According to the gate control theory, if peripheral pain signals are conveyed to the brain via thinner myelinated sensory nerve fibers or $A \delta$, while acupuncture stimulation is sent via $A \beta$ which has a higher speed, then the signal that comes from acupuncture stimulation will first arrive in the brain. This stimulation results in endogenous opioid and serotonin secretion in dorsal horn which acts as an inhibitor of intrinsic excitation [29].

At the central level, signals due to acupuncture are transferred from the peripheral to the central nervous system (CNS) thus affecting the release of pituitary hormones and endogenous opioids, such as endorphins, dynorphins, and enkephalin which play a role in pain modulation. There are several areas in the brain and spinal cord known as opioid action sites such as the hypothalamus, limbic system, basal ganglia and periaqueductal gray areas, raphe magnus nucleus, reticular activating system, and the dorsal horn of the spinal cord. Inhibition of pain at the brain level has been well understood through the role of endogenous opioids and the inhibitory descending pain system [29].

Endorphins are endogenous opioids released by the pituitary and hypothalamus. Although the role of plasma $\beta$-endorphins in pain regulation is unclear, many studies report that endorphins are closely related to pain levels in cancer patients, as well as in this study. Low frequency EA in LI4 in healthy people has a significant increase in plasma $\beta$-endorphins [30]. Stimulation of acupuncture at LI4 point increases the excretion of opioid peptides from the limbic system such as the hippocampus and PAG [19]. Plasma $\beta$-endorphin levels increase significantly after EA [31]. Electroacupuncture at low frequencies, i.e $4 \mathrm{~Hz}$, has been shown to stimulate the release of $\beta$-endorphins $[32,33]$.

In addition to measuring cancer pain and examining $\beta$-endorphin levels, this study examined the condition of patients in terms of QoL. Although there has been no consensus on the definition of QoL for cancer patients, but it is generally agreed that the QoL of cancer patients includes positive and negative subjective perceptions of aspects of cancer patient symptoms, including physical, emotional, social, and cognitive functions, and importantly, symptoms diseases and treatment side effects [34]. QoL consists of two components, such as subjective and multidimensional. Subjective factor refers to the fact that QoL can be understood only from the patient's perspective. Multidimensionality refers to the fact that QoL encompasses broad dimensions which can be grouped into one of four different areas such as physical, functional, emotional and social conditions. Therefore, QoL is associated with symptoms, functional, psychological and social welfare [35].

QoL currently becomes a parameter that is as important as treatment success characteristics such as average survival, disease-free conditions or controlled neoplasm conditions. In palliative medicine, the QoL of patients is used as a reference to determine whether palliative therapy can be continued, must be modified or stopped [34]. Cancer patients highly need calming actions to improve their body condition. Acupuncture is needed to overcome problems that arise due to changes in physical, psychological and social factors in cancer patients. Physical factors are influenced by the symptoms that occur due to cancer and the treatment obtained. Psychological factors are affected by anxiety or depression due to a sense of loss of hope, loss of control and freedom of activity. On the other hand, social factors are influenced by social difficulties in cancer patients [36]. Acupuncture improves the QoL for cancer patients in the symptom domain, such as fatigue, pain and depression [37]. Acupuncture will modulate the autonomic nervous system, interactions between autonomic nuclei in the brainstem, while the limbic system will be modulated by acupuncture to reduce symptoms such as nausea, vomiting, anxiety, and fatigue [38].

The limitations of our study include the number of samples, the longer follow-up time of the participants, our findings are even better when such comparators (healthy patients or control group) are available and need to inlcude its clinical significance. We suggest further studies to complement our research.

\section{CONCLUSIONS}

The combination of electroacupunture and medical treatment is proven to significantly reduce the pain score, increase the levels of plasma $\beta$-endorphins, and improve the QoL of stage III cervical cancer patients when compared to only given medical treatment. 


\section{ACKNOWLEDGEMENTS}

We would like to thank Fis Citra Ariyanto for providing suggestions and assistance in editing our manuscript.

\section{CONFLICT OF INTEREST}

The author declares no conflict of interest.

\section{ORCID}

Wita Saraswati, https://orcid.org/0000-0001-9754-5151

\section{REFERENCES}

1. National Comprehensive Cancer Network. Clinical Practice Guidelines in Oncology for Adult Cancer Pain. Available at: https://www.nccn.org/ [Date accessed: September 14, 2019]

2. van den Beuken-van Everdingen $\mathrm{MH}$, de Rijke JM, Kessels AG, Schouten HC, van Kleef M, Patijn J. Prevalence of pain in patients with cancer: a systematic review of the past 40 years. Ann Oncol 2007;18:1437-49.

3. Grossman SA. Assessment of cancer pain: a continuous challenge. Support Care Cancer 1994;2:105-10.

4. Mwaka AD, Orach CG, Were EM, Lyratzopoulos G, Wabinga $\mathrm{H}$, Roland M. Awareness of cervical cancer risk factors and symptoms: cross-sectional community survey in post-conflict northern Uganda. Health Expect 2016;19:854-67.

5. Twycross R, Harcourt J, Bergl S. A survey of pain in patients with advanced cancer. J Pain Symptom Manage 1996;12:273-82.

6. Weiss SC, Emanuel LL, Fairclough DL, Emanuel EJ. Understanding the experience of pain in terminally ill patients. Lancet 2001;357:1311-5.

7. Paice JA, Ferrell B. The management of cancer pain. CA Cancer J Clin 2011;61:157-82.

8. Shaheen PE, Legrand SB, Walsh D, Estfan B, Davis MP, Lagman $\mathrm{RL}$, et al. Errors in opioid prescribing: a prospective survey in cancer pain. J Pain Symptom Manage 2010;39:702-11.

9. van den Beuken-van Everdingen $\mathrm{MH}$, Hochstenbach LM, Joosten EA, Tjan-Heijnen VC, Janssen DJ. Update on prevalence of pain in patients with cancer: systematic review and metaanalysis. J Pain Symptom Manage 2016;51:1070-90.e9.

10. Cassileth BR, Deng GE, Gomez JE, Johnstone PA, Kumar $\mathrm{N}$, Vickers AJ. Complementary therapies and integrative oncology in lung cancer: ACCP evidence-based clinical practice guidelines (2nd edition). Chest 2007;132(3 Suppl):340S-354S.

11. Saraswati W, Dahlan EG, Saputra K, Sutrisno TC. Effect of electroacupuncture on natural-killer cells and tumor size in patients with cervical squamous-cell carcinoma: a randomized controlled trial. Med Acupunct 2019;31:29-36.

12. Liu Y, Wang H, Wang X, Mu L, Kong Q, Wang D, et al. The mechanism of effective electroacupuncture on $\mathrm{T}$ cell response in rats with experimental autoimmune encephalomyelitis. PLoS One 2013;8:e51573.

13. Saraswati W, Rosyiadi MR, Imandiri A. Electroacupuncture versus analgesics for patients with stage IIIB cervical cancer post cisplatin chemotherapy. Med Acupunct 2020;32:293-9.

14. Cheng LL, Ding MX, Xiong C, Zhou MY, Qiu ZY, Wang Q. Effects of electroacupuncture of different frequencies on the release profile of endogenous opioid peptides in the central nerve system of goats. Evid Based Complement Alternat Med 2012;2012:476457.

15. Hu C, Zhang H, Wu W, Yu W, Li Y, Bai J, et al. Acupuncture for pain management in cancer: a systematic review and metaanalysis. Evid Based Complement Alternat Med 2016;2016: 1720239 .

16. World Health Organization. Comprehensive Cervical Cancer Control: A Guide to Essential Practice, 2nd ed. Geneva: World Health Organization, 2014.

17. MacPherson H, Altman DG, Hammerschlag R, Youping L, Taixiang W, White A, et al. Revised STandards for Reporting Interventions in Clinical Trials of Acupuncture (STRICTA): extending the CONSORT statement. PLoS Med 2010;7:e1000261.

18. Taguchi R. Acupuncture anesthesia and analgesia for clinical acute pain in Japan. Evid Based Complement Alternat Med 2008;5:153-8.

19. Xia Y, Cao X, Wu G, Cheng J. Acupuncture Therapy for Neurological Diseases: A Neurobiological View. Heidelberg: Springer, 2010.

20. Zhao ZQ. Neural mechanism underlying acupuncture analgesia. Prog Neurobiol 2008;85:355-75.

21. Perwitasari DA, Atthobari J, Dwiprahasto I, Hakimi M, Gelderblom H, Putter H, et al. Translation and validation of EORTC QLQ-C30 into Indonesian version for cancer patients in Indonesia. Jpn J Clin Oncol 2011;41:519-29.

22. Chiu JH, Chung MS, Cheng HC, Yeh TC, Hsieh JC, Chang $\mathrm{CY}$, et al. Different central manifestations in response to electroacupuncture at analgesic and nonanalgesic acupoints in rats: a manganese-enhanced functional magnetic resonance imaging study. Can J Vet Res 2003;67:94-101.

23. Wang SM, Kain ZN, White P. Acupuncture analgesia: I. The scientific basis. Anesth Analg 2008;106:602-10.

24. Lee H, Ernst E. Acupuncture analgesia during surgery: a systematic review. Pain 2005;114:511-7.

25. Apriyanto, Srilestari A, Abdurrohim K, Pryambodho, Prasmusinto D. Effect of electroacupuncture on post-caesarean section pain. J Phys Conf Ser 2018;1073:062038.

26. Sun P. Management of Postoperative Pain with Acupuncture. Boston: Elsevier/Churchill Livingstone, 2007.

27. Paley CA, Johnson MI, Tashani OA, Bagnall AM. Acupuncture for cancer pain in adults. Cochrane Database Syst Rev 2015; 2015:CD007753. 
28. Choi TY, Lee MS, Kim TH, Zaslawski C, Ernst E. Acupuncture for the treatment of cancer pain: a systematic review of randomised clinical trials. Support Care Cancer 2012;20:1147-58.

29. Hidayat IT, Srilestari A, Simadibrata C, Purba JS. [Effect of wrist and ankle acupuncture for low back pain]. eJournal Kedokt Indones 2015;3:95-100. Indonesian.

30. Lufty Setiawardhani A. Electroacupuncture effect at LI 4 hegu point of plasma beta-endorphin level in healthy subject [master's thesis]. Jakarta: Universitas Indonesia; 2016. 71 p.

31. Groppetti D, Pecile AM, Sacerdote P, Bronzo V, Ravasio G. Effectiveness of electroacupuncture analgesia compared with opioid administration in a dog model: a pilot study. $\mathrm{Br} \mathrm{J}$ Anaesth 2011;107:612-8

32. Cheng RS, Pomeranz B. Electroacupuncture analgesia could be mediated by at least two pain-relieving mechanisms; endorphin and non-endorphin systems. Life Sci 1979;25:1957-62.

33. Lee HJ, Lee JH, Lee EO, Lee HJ, Kim KH, Kim SH, et al. Substance $\mathrm{P}$ and beta-endorphin mediate electro-acupuncture induced analgesia in mouse cancer pain model. J Exp Clin Cancer Res. 2009; 28(1):102. Retraction in: Lee HJ, Lee JH, Lee EO, Lee
HJ, Kim KH, Kim SH, et al. J Exp Clin Cancer Res 2009;28:137.

34. Sutrisno H, Dharmayuda TG, Rena RA. [An overview of the quality of life of non-Hodgkin's lymphoma cancer patients treated at Sanglah General Hospital Denpasar (Preliminary Study)]. J Peny Dalam 2010;11:96-103. Indonesian.

35. Saatçı E, Koçak Y, Bozdemir N, Akpınar E, Kalaylıŏlu-Wheeler Z. Effect of chemotherapy on quality of life in patients with lymphoma. Marmara Med J 2007;20:98-103.

36. Christiyawati MD, Yatmihatun S, Sumanto S. [Hypnopuncture therapy methods (hypnotherapy and acupuncture therapy) for improving the quality of life of uterine cancer patients postchemotherapy therapy in Surakarta city]. J Keterapian Fisik 2016;1:9-14. Indonesian.

37. Dean-Clower E, Doherty-Gilman AM, Keshaviah A, Baker F, Kaw C, Lu W, et al. Acupuncture as palliative therapy for physical symptoms and quality of life for advanced cancer patients. Integr Cancer Ther 2010;9:158-67.

38. Sagar SM. Acupuncture as an evidence-based option for symptom control in cancer patients. Curr Treat Options Oncol 2008;9:117-26. 